\title{
RFID Applications and Potentials
}

\author{
Joseph Barjis \\ Delft University of Technology \\ The Netherlands \\ J.Bariis@TUDelft.NL
}

Tel. +31152787184

Fax: +31 152783429

\author{
Samuel Fosso Wamba \\ (SISAT) \\ University of Wollongong \\ Australia \\ Samuel@uow.edu.au \\ Tel.: + 61242213136 \\ Fax: + 61242214045
}

School of Information Systems \& Technology

\section{Introduction}

The economy of the $21^{\text {st }}$-century enterprise is driven by efficiency, which, among other initiatives, requires enterprise business processes and workflows to be supported by adequate information technology to achieve this efficiency. Information technology plays a key role in transforming enterprises, especially through the way these enterprises conduct business and interact with partners and customers. Emerging technologies and their innovative applications in business and industry have been creating an unprecedented potential to grow, extend, and retain competitive spot in the market. One such a technology that sets a new wave of conducting business and forming relationship among networked enterprises along their sophisticated supply chain is RFID. RFID (Radio Frequency Identification) technology today stands at the crossroads of a shift and transformation to a new wave of relationship in both business and industry - a wave where real-time monitoring, speed of processing, accuracy of data are becoming the only way forward in this competitive market. In the current market, the RFID technology demonstrates its application potential in every sector of the economy, business and industry, such as transportation and cargo, storage and retail, healthcare, manufacturing, and many other sectors and domains, including even documents, ID cards, items of fashion and design. Although still in its infancy, the current research manifests that the use of RFID can significantly transform the current way of conducting business, improve efficiency of operation and management, and support decision-making processes. But, it is not a surprise that IT diffusion is a longitudinal process and takes many years and decades. In particular, it requires the efforts of both researchers and practitioners to study and unveil the potentials of new technologies and document their innovative applications in enterprises. Thus, RFID Applications and Potentials rightfully require profound research, academic, and entrepreneurial attention. 
With this aim in mind, we have launched this special issue to solicit new findings and research results on RFID Applications and Potentials, and RFID projects in general. The selected articles for this special issue are rather making a complementary contribution to a better understanding of, and an insight into, the applications and potentials of RFID technology.

All articles submitted to this special issue went through a rigorous review process in three rounds, with a minimum of three reviewers per article. Only the most relevant papers were selected for publication in this special issue.

\section{Papers in this Issue}

Papers put together in this section are rather of an inclusive character in relation to the RFID Application and Potentials. The selected papers, in a complementary manner, address different aspects of RFID technology which are pertinent to its application and potentials.

In the first paper, which is entitled "Understanding the organizational impact of radio frequency identification technology: a holistic view", Xihui Zhang, David W. Nickels, Thomas F. Stafford discuss the application of RFID technology and its potential from a broader view. This paper provides an introduction to RFID technology and surveys a variety of its applications. Furthermore, the paper discusses the impact of RFID technology on organizational IT infrastructure, business intelligence, and decision-making. The findings of this paper should definitely be important to researchers and practitioners. For researchers, it introduces a conceptual research framework and a series of proposals that can guide future studies. As for practitioners and future RFID project managers, the findings of this paper have a cautionary function about the full depth and breadth of potential issues arising from RFID adoption. As the authors warn, the value of RFID-enabled real-time response to a full range of operational and competitive factors is undeniable, but the way forward to achieving these ends becomes clear only with consideration of the implications of the full "IT Decision Chain".

In the second paper, which is entitled "Implementing RFID in production systems: a case study from a confectionery manufacturer", Chris Kürschner, Alexandra Brintrup, Paul Bowman, Erica Dubach, and Frédéric Thiesse discuss a case study describing an RFID project for container tracking system. In particular, the paper focuses on the management of the RFID project and the system design. It further gives an economic evaluation of the implemented RFID system and contrasts it with the pre-RFID situation. The discussion of RFID system and its implementation is given from a multi-perspective - researcher and practitioner perspective. For data gathering, the paper uses interviews with the 
management to document the findings and related observations, which adds to the practicality of the findings as the lessons learned.

The third paper, which is entitled "RFID technology adoption in New Zealand's supply chains: a case study approach" and is authored by Chin-Boo Soon and Jairo A. Gutiérrez. Drawing on several technology adoption theories, this paper presents the findings of a study on RFID adoption in New Zealand's supply chains. The authors identified three important factors to be considered in the adoption of the technology, namely, 'compatibility', 'facilitating condition', and 'readiness'. Their findings suggest that the application of these factors to the firm and its environment helps to evaluate the issues surrounding the firm's ability to innovate. The authors found for example that RFID was simply not suitable in some business scenarios or was not compatible with some existing supply chain applications. Another finding was that there was a perception of little support for the deployment of RFID at various points in a supply chain, and that supply chain partners were waiting for each other to deploy or initiate RFID.

Hiroyasu Yuhashi and Junichi lijima conclude this special issue with their article entitled "The power to activate a creative core in enterprise", which focuses on the mechanisms to activate a 'creative core' within firms in a context of social networking. The authors argue that social networking among employees is a platform for creativity; so when management supports such social networks, the strength of the organization increases. More specifically, the authors present a quantitative association from their previous research and a theoretical contemplation to provide a management method between the communication of employees and organizational collaboration. Using a case analysis of company, which is an ICT system integrator, and an RFID system, the authors explored whether or not there were causal relationships through a multiple regression analysis of Bayesian statistics. They arrived at the conclusion that the egocentric collaboration networks of the 'creative core' grew by activating communication (sending of emails) among employees.

\section{Acknowledgement}

The guest editors would like to express their sincere gratitude to all contributors, especially the authors who enthusiastically contributed to this special issue with their newest and revised findings on this promising technology, the reviewers who allocated their time to share their expertise with the authors and help in the selection of the related papers, and lastly the journal's editor-in-chief, Professor Ting-Peng Liang and the production team. 


\section{About the Guest Editors}

Dr. Barjis is an Associate Professor of Modeling and Simulation in the field of Systems Engineering, at Delft University of Technology (The Netherlands). His research is focused on business process modeling and simulation, healthcare processes modeling and simulation, security driven software engineering, enterprise engineering, information systems design, system analysis and design, collaborative, participative, and interactive modeling. Dr. Barjis is founder and current chair of the Association for Information Systems Special Interest Group on Modeling and Simulation - SIGMAS (http://www.AIS-SIGMAS.org/); founder of the International Workshop on Enterprise \& Organizational Modeling and Simulation (http://www.EOMAS.org/); member of several international professional organizations; member of Program Committee and Editorial Board in several international conferences and journals; frequently invited guest editor for International Journals. Dr. Barjis published 13 edited conference/scientific books, 14 book chapters, 20 journal articles (including editorial), guest editor of 9 special issues, and dozens of fully peer refereed international conference papers.

For further information, refer to Barjis' personal webpage: http://www.JosephBarjis.com.

Dr Samuel Fosso Wamba is a Senior lecturer at the School of Information Systems \& Technology (SISAT), Australia. He earned an MSc in mathematics, from the University of Sherbrooke in Canada, an MSc in e-commerce from HEC Montreal, Canada, and a Ph.D. in industrial engineering, from the Polytechnic School of Montreal, Canada. His current research focuses on business value of IT, inter-organisational system (e.g., RFID technology) adoption and use, supply chain management, electronic commerce and mobile commerce. $\mathrm{He}$ has published papers in a number of international conferences and journals including European Journal of Information Systems, International Journal of Production Economics, Information Systems Frontiers, Journal of Theoretical and Applied Electronic Commerce Research, Proceedings of the IEEE, Hawaii International Conference on Systems Science (HICSS) and Americas Conference on Information Systems (AMCIS). Dr Wamba is organizing special issues on RFID for the Business Process Management Journal and Pacific Asia Journal of the Association for Information Systems. He has been served as mini-track organizer and chair on the same topic for the 15th Americas Conference on Information Systems (AMCIS), The $6^{\text {th }}, 7^{\text {th }}$ and $8^{\text {th }}$ Workshops on e-Business, A Pre-ICIS Workshop Sponsored by AIS SIGeBIZ. He is CompTIA RFID+ Certified Professional, Founder and CEO of e-m-RFID.biz, and can be contacted at samuel@uow.edu.au 